\title{
Barriers Inhibiting Inquiry-Based Science Teaching and Potential Solutions: Perceptions of Positively Inclined Early Adopters
}

\author{
Michael Fitzgerald ${ }^{1}$ (D) Lena Danaia $^{2}$. \\ David H. McKinnon ${ }^{1}$
}

Published online: 22 July 2017

(C) The Author(s) 2017, corrected publication 2019

\begin{abstract}
In recent years, calls for the adoption of inquiry-based pedagogies in the science classroom have formed a part of the recommendations for large-scale high school science reforms. However, these pedagogies have been problematic to implement at scale. This research explores the perceptions of 34 positively inclined early-adopter teachers in relation to their implementation of inquiry-based pedagogies. The teachers were part of a large-scale Australian high school intervention project based around astronomy. In a series of semistructured interviews, the teachers identified a number of common barriers that prevented them from implementing inquiry-based approaches. The most important barriers identified include the extreme time restrictions on all scales, the poverty of their common professional development experiences, their lack of good models and definitions for what inquiry-based teaching actually is, and the lack of good resources enabling the capacity for change. Implications for expectations of teachers and their professional learning during educational reform and curriculum change are discussed.
\end{abstract}

Keywords School science $\cdot$ Secondary/high school $\cdot$ Teacher beliefs $\cdot$ Inquiry-based science teaching $\cdot$ Astronomy education

\section{Introduction}

Inquiry-based learning has been both a buzz term and a key focus for twenty-first-century science teaching reform (Furtak et al. 2012a; Marshall et al. 2016; National Research Council

Michael Fitzgerald

mfitzasp@gmail.com

1 Edith Cowan Institute for Education Research, Edith Cowan University, Joondalup, WA 6027, Australia

2 School of Teacher Education, Charles Sturt University, Bathurst, NSW 2795, Australia 
2000; Tytler 2007). There is confusion and often inconsistency within the literature in relation to what constitutes inquiry-based learning and how the term is defined (Furtak et al. 2012b; Marshall et al. 2016). For some, it simply means hands-on or active learning (Bonwell \& Eison 1991) while others define it more in the open-inquiry sense that involves students generating questions, designing the method of inquiry, conducting the investigation, answering their original question, and in the process, finding out that even more needs to be considered (Krajcik et al. 2000). Given the lack of consensus, we adopt the traditional approach of defining inquiry-based learning in science education as encompassing four different levels. These levels, which are briefly outlined below, initially stem from the work of Schwab (1962) and Herron (1971) and have been used in many different formats over the intervening decades.

1. Confirmation inquiry: students are provided with the question and procedure, and the results are known in advance.

2. Structured inquiry: students are provided with the question and procedure but have to generate an explanation supported by the evidence they have collected.

3. Guided inquiry: students are provided with the research question and they design the procedure to test their question and generate explanations.

4. Open inquiry: students derive questions, design and carry out investigations, and communicate their results. A feature of this level of inquiry is that there is no prescribed target or result.

In Australian science classrooms, a common approach to inquiry is through the use of the 5E instructional model (Bybee 1997; Bybee et al. 2006). This student-centred approach to teaching and learning engages students in their learning, recognises their existing knowledge and beliefs, and allows them to explore the phenomenon before developing science explanations and representations of their developing understandings. The elaborate phase of the model allows them to extend their understandings through student-planned investigations. The final evaluation phase involves students representing their conceptual understandings and reflecting on their learning journey.

Marshall et al. (2016) describe "contemporary models of inquiry-based instruction" and provide a definition of "proficient inquiry-based instruction" that is consistent with the more open forms of inquiry and which we adopt for the purpose of this paper:

[inquiry based instruction is an]...intentional student-centered pedagogy that challenges the learner to explore concepts, ideas, and/or phenomena before formal explanations are provided by the teacher and/or other students. Within this definition of inquiry, students engage with one or more of the scientific practices (as defined by NGSS) while studying one or more science concepts (as defined by NGSS). (Marshall et al. 2016, p. 4).

Australian national reports on school science education typically call for the more studentcentred, open forms of inquiry, yet these approaches seem to be rarely undertaken in the typical science classroom (Goodrum \& Rennie 2007; Goodrum et al. 2001; Tytler 2007) with even larger barriers seen in lower socioeconomic, remote, or rural schools (e.g. Townsend et al. 2017). These mirror calls that are very similar to those science education reports published internationally (e.g. American Association for the Advancement of Science (AAAS) 1990; Committee for the Review of Teaching and Teacher Education (CRTTE) 2003; Drury and Allen 2002; International Bureau for Education 2001; Millar and Osborne 1998), European Commission 2007; Select Committee on Science and Technology 2002). Instead, transmissive 
approaches are adopted that involve students spending most of their time copying notes (Danaia et al. 2013). When they have the opportunity to undertake practical work, it is often teacher directed and categorised at the confirmation inquiry level described earlier. Osborne (2006 p. 2) characterises this approach as one that “...provides uninteresting answers to questions never asked" by students.

In Australia, the recently (2014) enacted national Australian Curriculum: Science (ACARA 2014) contains three interrelated strands, one focussing largely on content knowledge and one focussing on the nature and influence of science and science inquiry skills, which focusses on skills essential for working scientifically. This statement, with its emphasis on building inquiry skills rather than undertaking the inquiry process, does make it sound somewhat distinct from what would be considered true inquiry learning. There has also been some concern that the organisation of the elements of the inquiry process across the various year levels is not reasonably aligned while also has some glaring omissions (Lupton, 2014). Regardless of its interpretation, Australian teachers and schools are now mandated to incorporate inquiry at some level into their regular classroom practice in a similar way to the Next Generation Science Standards (NGSS 2013) calls for in the USA.

There are some, such as Settlage (2007), who consider inquiry-based learning, particularly of the open-inquiry variety, to be an unrealistic mythology rather than a practical approach to high school science education. Others have suggested that inquiry-based teaching does not provide students with either the scaffolds needed in order to learn specific concepts or the processes of science. As a consequence, they tend to favour or advocate for direct instruction and transmission over inquiry-based approaches (Kirschner et al. 2006; Mayer 2004). An independent review commissioned by the, then conservative, government of Australia (Australian Government: Department of Education and Training 2014) of the Australian Curriculum also contained much scepticism of inquiry-based or constructivist pedagogies. This debate may even be a moot point as it is nearly tacit, albeit anecdotal, knowledge amongst researchers in the field that true inquiry-based teaching rarely occurs in actual classrooms, a truism backed up by empirical studies (Danaia et al. 2013; Capps \& Crawford 2013).

Calls for the professional development of teachers to increase the implementation of inquirybased learning have been common over the last few decades (Marshall et al. 2016). However, research into the professional development (PD) of teachers about the topic of inquiry-based teaching and learning has generally painted a fairly bleak picture (Capps et al. 2012). Many teachers have continued to be largely dissatisfied with the PD experiences presented to them (e.g. DarlingHammond et al. 2009; Dillon et al. 2000; Penuel et al. 2007). In Australia, national bodies have taken the crucial step of making PD a requirement of teacher accreditation (e.g. Commonwealth Government 2007), yet there are few studies that report on effective PD approaches which have been successful in generating wide-scale, lasting change to practice. The dominant short-term approach to PD, such as the typical hypodermic one-day face-to-face session where teachers are talked at and expected to go away and implement approaches talked about, tends not to result in changes to teachers' practice (Yoon et al. 2007). It would seem that teachers need ongoing, sustained support (Blank et al. 2008) in order to transform their practice.

Even when science teachers' PD experiences have been perceived in a positive light, they generally get the rug swept out from underneath them by more pressing concerns in the classroom upon their return to the school (e.g. Lumpe et al. 2000). With the reality of the time constraints imposed by the context of available contact hours, teachers generally find it hard to translate their PD experiences into the reality of the classroom. This difficulty can also make it hard for intended improvements to spread naturally throughout the population of science 
teachers where large-scale uptake relies heavily on their perception of the success of an approach before trialling it themselves (Hall \& Hord 2001).

It would seem that there are other barriers to implementing inquiry-based approaches. Marshall et al. (2016) highlight some of the challenges that have been reported in the literature and which need to be considered for reform to become widespread and sustained. One concern relates to teachers having low personal science teaching efficacy beliefs and limited pedagogical content knowledge in implementing inquiry-based instruction. The current standardised testing regime also threatens inquiry-based reform given that transmissive approaches are employed to cover the content to ensure students' success in the recall of knowledge on tests. As has been known for some time, the significant changes called for in most reforms involving inquiry-based learning have typically not come to pass (Anderson \& Helms 2001).

In this paper, we complement and extend the aforementioned findings by exploring the barriers and issues that Australian teachers perceive as preventing them from undertaking inquiry in high school science classes. We begin by explaining the context and aims of an intervention within which this study is situated and define the sample of teachers that we have interviewed. We then explain the nature of the interview process itself as well as exploring the two separate analytic methods used to extract conceptual and relational meaning from the qualitative data. We then explore and explain the links and concepts identified through these analyses before discussing their implications for inquiry-based interventions.

\section{Research Context and Aims}

\section{Project Context}

This research was undertaken in the context of a large-scale \$2.4 million high school Astronomy Research in the Classroom style project (ARiC; Fitzgerald et al. 2014) implemented in the state of New South Wales (NSW), Australia (Danaia et al. 2012). This project, like other ARiC projects, focusses on using authentic instrumentation and data to support higher-level inquiry-based approaches to astronomy in the classroom. The project was co-funded by the Australian Research Council (ARC) and the educational jurisdictions of the Catholic Education Offices of Parramatta and Bathurst and the NSW Department of Education and Training (DET) Western region. It was jointly run through Macquarie University and Charles Sturt University with the Las Cumbres Observatory Global Telescope Network (LCOGT, Brown et al. 2013) also providing both significant financial and organisational input in the form of access to their telescopes.

The project's official start date was in July 2009. First estimates of the intended number of participants were around 40 schools, 200 science teachers, and 9000 students from years 9 to 12 . By mid-2010, it was clear that the number of teachers interacting with and using the project materials originally created in an earlier investigation was far fewer than anticipated. There appeared to be a variety of barriers that were not being addressed leading to a major lack of uptake by science teachers. In an attempt to understand the factors inhibiting the uptake, we conversed with, at length, 34 teachers. The analysis of these interviews was undertaken in mid-2010. These earlier interviews were not recorded and are not included in the analyses reported below. Consequently, the project focus was changed significantly. Two of the project team undertook an extensive rewrite of the educational materials used (Fitzgerald et al. 2015). In addition, the PD model was reconceptualised and the approach to recruiting teacher participants was addressed. Subsequently, more formal interviews were planned and undertaken using a systematic semi-structured approach. 


\section{Participants}

The participants in this research are an opportunity sample of 34 science teachers within the three educational jurisdictions who were willing to engage with the reconceptualised intervention project and to commit to 3 to 5 days of funded face-to-face PD. Table 1 presents the demographic data of those involved in this research. All teachers were employed full time with most (58\%) coming from the catholic sector. The majority (30) held a Bachelor of Science or Bachelor of Applied Science degree. Of these 34 teachers, only two had not implemented due to their perception that the materials and the investigative projects were "inferior" and only one teacher had been prevented by external factors from implementing the project materials in any way. The interviews were conducted over the period October 2011 to April 2012.

\section{Method}

\section{Interviews}

Interviews were conducted with the 34 teachers at their respective school campus during one of their non-teaching periods and recorded with the respondents' permission. The median length of an interview was 1 hour (h), with the shortest being 40 minutes (min) and the longest $2 \mathrm{~h}$. The

Table 1 Demographics of participants in this research

\begin{tabular}{|c|c|c|}
\hline \multicolumn{2}{|l|}{ Demographic } & \multirow{2}{*}{$\frac{\text { Number }}{19}$} \\
\hline Gender & Male & \\
\hline & Female & 15 \\
\hline \multirow[t]{3}{*}{ Type of school } & Independent & 6 \\
\hline & Catholic systemic & 20 \\
\hline & Government & 8 \\
\hline \multirow[t]{4}{*}{ Age } & Under 30 & 2 \\
\hline & $30-40$ & 12 \\
\hline & $40-50$ & 8 \\
\hline & $50+$ & 12 \\
\hline \multirow[t]{2}{*}{ Position } & Classroom teacher & 20 \\
\hline & Head of department & 14 \\
\hline \multirow[t]{4}{*}{ Educational backgrounds } & Bachelor of Education (Applied Science) & 7 \\
\hline & Bachelor of Science, Diploma of Education & 24 \\
\hline & + Grad Certificate of Education & 2 \\
\hline & $+\mathrm{PhD}$ & 1 \\
\hline \multirow[t]{5}{*}{ Years teaching science } & Less than 1 year & 1 \\
\hline & 4-7 years & 5 \\
\hline & $8-12$ years & 4 \\
\hline & $13-25$ years & 11 \\
\hline & 25 years + & 13 \\
\hline \multirow[t]{6}{*}{ Years teaching at that school } & Less than 1 year & 5 \\
\hline & $1-3$ years & 7 \\
\hline & $4-7$ years & 5 \\
\hline & $8-12$ years & 8 \\
\hline & $13-25$ years & 7 \\
\hline & 25 years + & 2 \\
\hline \multirow[t]{2}{*}{ Any astronomy in science degree? } & Yes & 10 \\
\hline & No & 24 \\
\hline
\end{tabular}


interviews were semi-structured in the sense that broad themes had been chosen beforehand with the interviewer having a list of potential questions from which to choose if a lull in the conversation occurred. Thus, the interviews progressed in a naturalistic conversational fashion with a teacher's responses being more open ended and addressing topics at will, rather than being led.

The major themes addressed in the interview process surrounded inquiry-based learning and the contextual factors that may impact upon implementing this. As the teachers were involved with a particular inquiry-focussed astronomy education project, experiences related to the project functioning did surface, such as the nature of their professional development both in the current project and previously, as well as the reasons they became involved in this particular project. Contextual factors were also probed that influenced teachers' abilities to improve or change their practice and their general perceptions of their students' and classrooms, as well as their general employment, education, and life history.

All interviews were transcribed by an independent transcription agency. Initially, two actions were performed on the data. First, any irrelevant off-topic or social-conversation text was removed. Second, sections of text that were perceived to be on a general overarching topic, e.g. student motivation, were sorted and copied into a separate file. These paragraphs were tagged with the interviewee's name for later cross-reference, if required, as well as keeping the interviewer/ interviewee identification tags to separate this text for later analyses. The final text of on-topic interview conversation amounted to just over 200,000 words for the 34 interviews. Two methods of analysis of these textual data were undertaken. The first was undertaken manually in a traditional coding approach as an exploratory analysis while the second, using a textual analysis software Leximancer (www.leximancer.com), was used as a confirmatory analysis as a test to identify any potential personal bias arising from using the first approach.

\section{Manual Coding Exploratory Analysis}

The manual analysis method involved coding the text in a traditional tagging manner. The purpose of this was to identify any apparent general concepts discussed and examples of the representative text recorded in a separate document for later elaboration. The apparent links amongst these concepts/topics were identified together with the number of teachers who had made that particular link and quantified using a simple frequency count.

In order to generate a visual representation of the relationships amongst the concepts and the frequency of their links, these data were subsequently imported into Gephi, an open source graphical visualisation and manipulation package (https://gephi.org/). The data were organised using a "force-based algorithm" (Jacomy et al. 2011) designed to allow a broad qualitative interpretation and overview of the data. It is not easy to capture the complexity of the data presented by Gephi in a traditional print media journal article due to its multidimensional nature; hence, we supply the Gephi graph file as supplementary material for readers to explore.

The resulting Gephi network representation is presented in Fig. 1. Here, each of the circles represent the individual concepts identified. The raw frequency of how many times a particular concept was linked is represented by the size of the circle. The larger the circle, the more commonly the concept was linked to another. The largest circles were naturally formed as they were a central point of the broad exploratory themes of the interview.

The width of the lines connecting each circle is directly proportional to the frequency count of teachers who made the link between the two concepts. For instance, the link between "diffusion" and "supervisor support" has a very broad line connecting these two circles. This means that many teachers made the connection between these two concepts. In contrast, there is only a thin line 


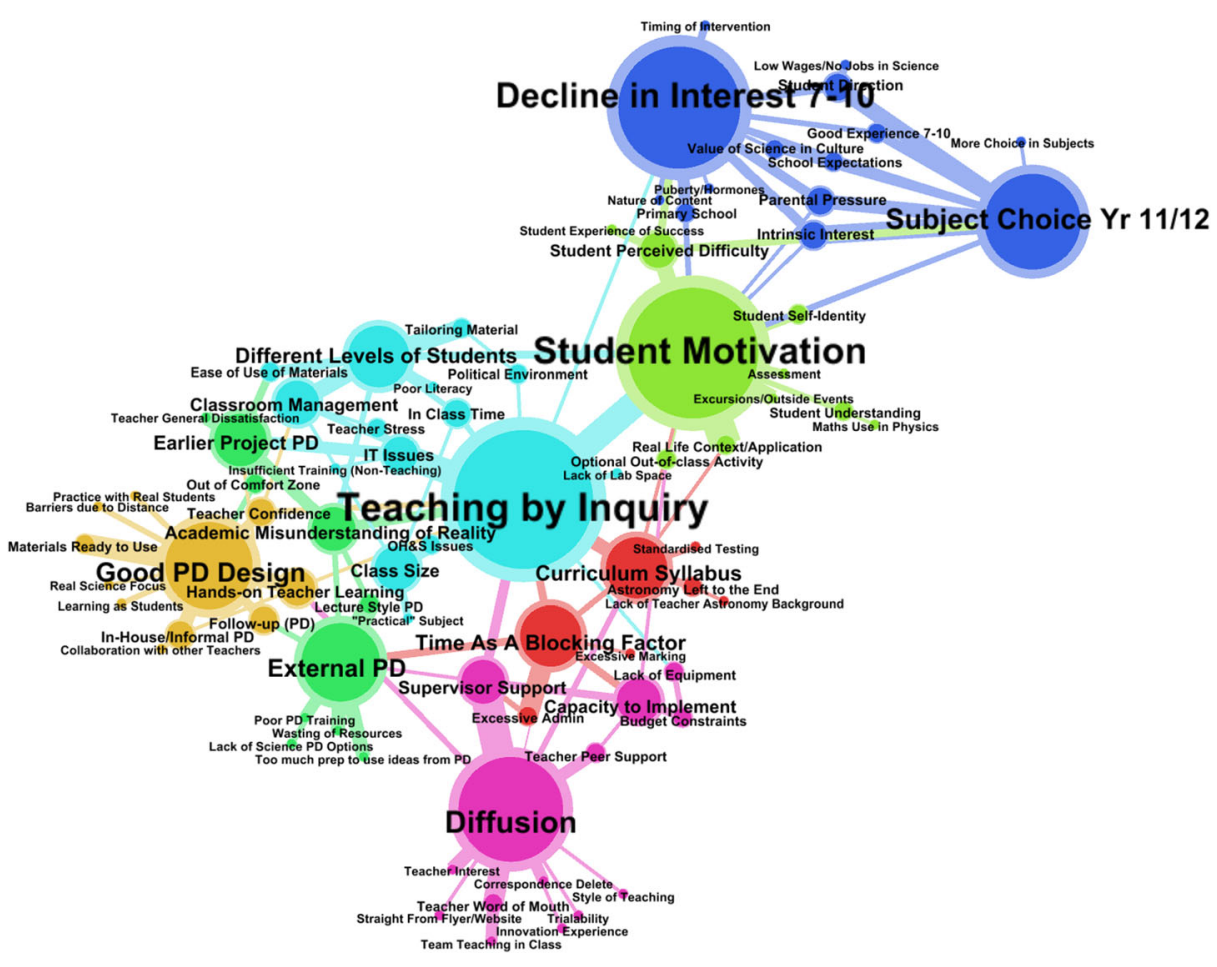

Fig. 1 Gephi communities of concepts

between "teaching by inquiry" and "decline in interest 7-10", indicating that while a link was made between these two concepts, it was not made by very many teachers.

\section{Automated Bayesian Confirmatory Analysis}

As a comparative and confirmatory analysis, a separate method was used to explore the same interview data. Leximancer, a text analysis tool, was employed to identify the underlying conceptual and thematic structure without any human intervention. Leximancer has one major advantage as it avoids human bias and interpretation of words and looks purely at the relationships of words within sentences to identify concepts and themes. Concepts and themes are identified using Bayesian probabilities based on the distance between words in a sentence. That is to say, Leximancer identifies a "concept" when two or more words continue to occur within a certain distance (set in the rules) within a sentence. "Themes" are similarly identified when "concepts" occur within a certain distance of each other. Figure 2 displays the Leximancer representation of the data. Overlaid are the straight lines representing the similar conceptual territory as the previously identified broad Gephi themes. The large ellipses represent the only areas not identified as themes in the manual coding analysis.

\section{Results}

"Communities of concepts" within the manual coding exploratory graph in Fig. 1 were explored. A "community" is defined as a set of concepts that are broadly connected. 
Fig. 2 Leximancer representation of the data. Overlaid are the black lines representing the similar conceptual territory as the broad Gephi themes. The red circles represent the only areas not identified as themes in the manual coding analysis

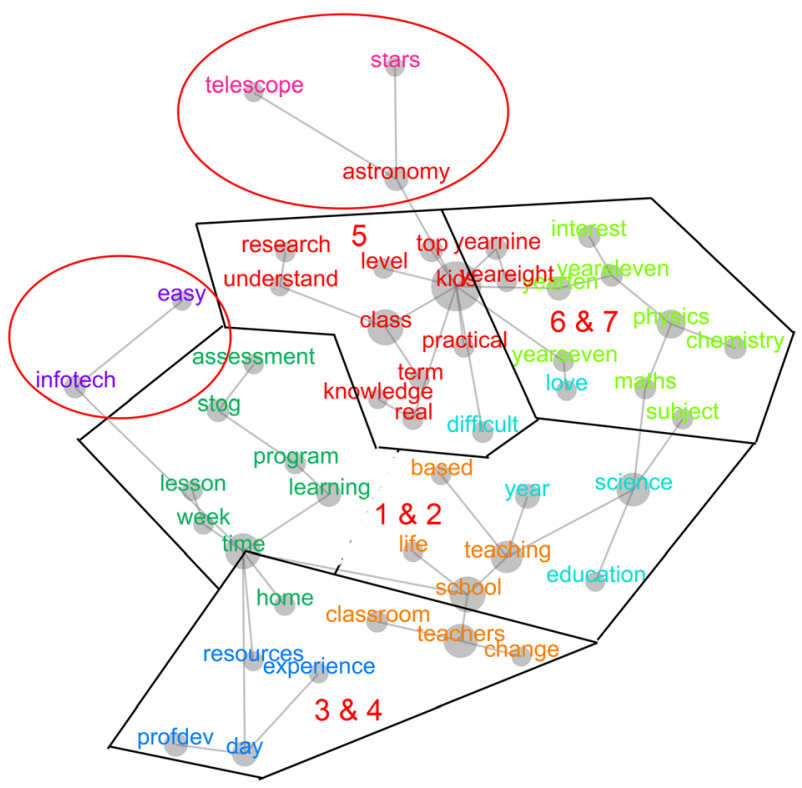

They may also be termed "themes" in Leximancer. Thus, the different colours in the graph represent these broader themes comprised of interrelated concepts. The general principle behind this technique, using the in-built algorithm outlined in detail by Blondel et al. (2008), is to progressively define increasingly larger themes from the initial nodes with the goal of finding the local maxima of modularity for each community. In this sense, it is somewhat like a k-means cluster analysis commonly employed in the Statistical Package for the Social Sciences (SPSS). Using this approach, seven distinct themes were identified and are outlined in Table 2. Each of these themes is represented by a separate colour in Fig. 1 .

To confirm the identified themes within the data which were identified using the manual exploratory coding method, Leximancer was also used to code automatically and to identify themes based purely on the lexical distances between frequently used words to identify concepts and the distance between these to identify themes. In Fig. 2, the Leximancergenerated map of concepts is represented as small circles and labels that are colour coded with the same colour to represent the Leximancer-identified themes.

The areas that correspond to the Gephi-identified themes are overlaid as black lined polygons for comparison. While the correspondence is not exactly one to one, there is a high

Table 2 Identified communities of concepts as broad themes

\begin{tabular}{ll}
\hline Theme & Gephi theme \\
\hline 1 & Diffusion-related \\
2 & Curriculum/school factors \\
3 & External/typical PD experiences \\
4 & Good PD design \\
5 & Teaching by inquiry \\
6 & Student motivation \\
7 & Decline in interest over 7-10 \\
\hline
\end{tabular}


degree of agreement on the broad issues. There is a single group identified in the Leximancer analysis that was not apparent in the Gephi data: the theme associated with "astronomy, telescope, and stars". The reason for this is quite simple: this is the core theme of the inquirybased project itself and was not coded by the authors in the initial textual analysis.

As can be seen in Fig. 2, in the Gephi analysis, there are two distinct super-groups of communities of concepts, that of the teachers to the upper right and those concerning the students on the lower left with "teaching by inquiry" forming the major link between the two. While not as pronounced, the Leximancer graph is also two sided with the students to the top right and the teacher issues largely to the lower left. As these two super-groups deal with two easily separable groups of concepts, we chose to focus on the teacher-focused group of concepts in this paper.

The size of a theme in Leximancer is set by the user. That is to say, through trial and error, the number of concepts within a theme can be adjusted to something that "makes conceptual sense". In contrast, Gephi calculates the themes purely from the data. Thus, the themes identified in Gephi are perhaps more representative of the true theme size encoded within the data but with the caveat that this may open to bias. Nonetheless, the correspondence with the automatic analysis conducted by Leximancer is large enough to indicate that researcher bias in the interpretation of the transcripts was low.

In this section, we step through these themes exploring the connections made between concepts by the teachers in a short summary and providing more detailed elaboration, including direct quotations, for each of these major themes. The direct quotes presented here from the teachers have been anonymised by use of a numerical code (e.g. $\left.\mathrm{T}_{3}\right)$.

\section{Teaching by Inquiry}

Teaching by inquiry forms the centrepiece of the dataset as this was the most commonly connected concept and theme (Fig. 3). A lot of the most closely linked concepts involve the very close direct mechanics of getting inquiry teaching working in the classroom. These include occupational health and safety (OH\&S) and information technology (IT) issues and lack of in-class time, class size, and classroom management as well as insufficient training and teacher stress. However, prior to making these links, teachers sometimes needed some clarification on the actual meaning of "teaching by inquiry". Many teachers were not confident in defining what "inquiry-based learning" actually means or what it involves. For some, it is a synonym for active learning or hands-on learning, while others are simply not quite so sure.

Well we've all heard about it [inquiry based instruction]. What we really need is just some models...some examples... and some training on how to write the activities and how to structure them. If I had that basic tool kit I'd be able to do it myself... .confidently. At the moment I'm like...I don't know how to do it. I wish I could go to a few workshops or something and learn how to...how to construct these things. I think it's probably quite simple. I just...it's probably more of a confidence thing. $\left(\mathrm{T}_{1}\right)$

The nature of class size, which tends to be about 30 students for a typical year 7-10 high school classroom, is perceived to be an impediment to inquiry-based learning. In such large classes, it is less likely that the teacher can provide individual and/or small group help with their experimental skills, an area identified as particularly necessary for modern Australian 


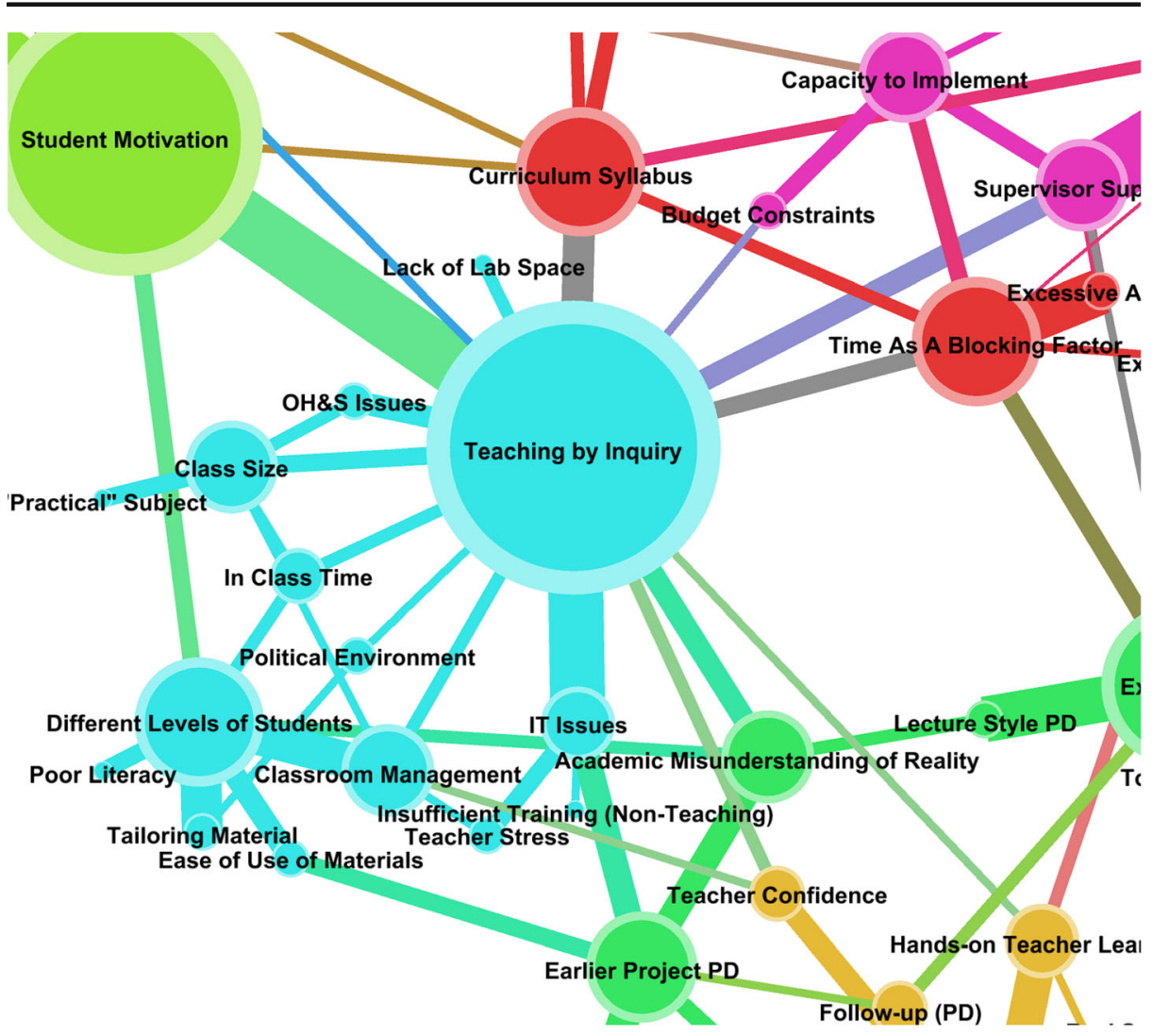

Fig. 3 Teaching by inquiry theme and connected concepts

students (DEST 2006). This is despite the fact that other subjects with a heavy hands-on aspect, such as visual art, industrial technology, or even information and software technology classes, are classified as practical subjects and often have their maximum class size capped at 24. The larger the class size is, the less safe the laboratory environment is perceived to be.

Well one of the biggest glaring problems that comes up is trying to do experiments and practical work. If you had a class of 24 that's three kids to a bench. Three kids in a group is a good number of kids so that everybody has a job to do. As soon as you get four kids at a group you've got somebody doing nothing. And if there's a kid doing nothing, that's generally when accidents and mistakes will happen. And so what happens is whenever my classes are doing experiments, I'm not helping them with their experiments. I'm standing back trying to manage the whole class and keep a very close eye on safety. $\left(T_{2}\right)$

The opportunity to do hands-on work has also been reduced due to the high level of organisational overhead due to $\mathrm{OH} \& \mathrm{~S}$ issues. This applies to all sciences but it is particularly acute in chemistry where the safety requirements have become stringent and prevent the use of certain chemicals and equipment, easily accessible in previous eras, and leading to some teachers having to show YouTube video clips rather than allowing students to perform the actual experiments. $\mathrm{OH} \& \mathrm{~S}$ issues also impact on the capacity to run excursions such as field trips to a planetarium or observation nights where risk assessments need to be undertaken for 
every external opportunity offered. This adds another layer to the administrative loads with which teachers are confronted.

See, for every prac we do a - oh god, it just escapes me - we do an awareness...an $\mathrm{OH} \& \mathrm{~S}$ sheet. We do the same experiments every year, yet we're forever writing out the same $\mathrm{OH} \& \mathrm{~S}$ sheet. I mean, to me it seems ridiculous...for every prac you attach your $\mathrm{OH} \& \mathrm{~S}$ sheet. It's just what you do but that's another time-consuming thing. $\left(\mathrm{T}_{3}\right)$

IT issues also figured prominently in the interviews. In the context of astronomy, all image data are digital and are transported, manipulated, and measured on computers. What little capacity there is to take visual non-computational measurements can only be done out of school hours, i.e. at night time. So, perhaps more than other sciences, astronomical measurements depend heavily on reliably functioning software. All of the teachers expressed significant frustration at achieving stable functionality with the IT hardware and software in their schools. These issues caused a great deal of stress for those teachers who encountered problems. Many also commented that insufficient training was generally provided for the new IT that was rolled out to schools, both hardware and software. During the period of this research, funding for laptops for each student in Australia was provided by the Australian government, but no IT support or funding was provided.

So, we like the idea of IT and the kids have all got laptops and we thought they might have been an opportunity to use the laptops for proper learning and the potential was there of course, but in practice they are very limited to them because you can't put any [additional] software on them. $\left(\mathrm{T}_{4}\right)$

\section{Earlier/External PD}

The typical approach suggested to promote inquiry-based learning is the provision of highquality "professional development experiences" (Loucks-Horsley et al. 2003) As we can see in the clustering of the two themes, there is a relatively negative (green) actual theme exploring the varieties of professional development that the teachers typically experience in contrast to a relatively positive (yellow) ideal theme where they are describing their preferred and best professional development experiences (Fig. 4).

Broadly, the actual theme describes the typical PD experienced by these teachers. Essentially, they were heavily lecture driven with little actual training and which required too much post-PD work to implement any of the ideas from the session. This was seen as a large waste of teacher resources in terms of their time. In large part, this was related to the disconnect between what academic education people from the universities provided and what the teachers expected. To illustrate the actual experience, one teacher's succinct description of a typical PD day is a "bunch of lectures and a nice lunch in between".

Very few presenters practise what they preach. I can’t even think of ever going to a workshop about some sort of active learning where we actually did some active learning. Most people stand up and talk about it, and say how much of a good idea it is, but they're not actually doing it with the teachers. $\left(\mathrm{T}_{5}\right)$

The teachers in this study largely had low opinions of the quality of the training they had previously been exposed to and consider some of them to be a significant waste of resources with respect to both time and money. More specifically, their general experience is that while attending a PD day, the focus or content covered inspires them and they leave with good intentions and 


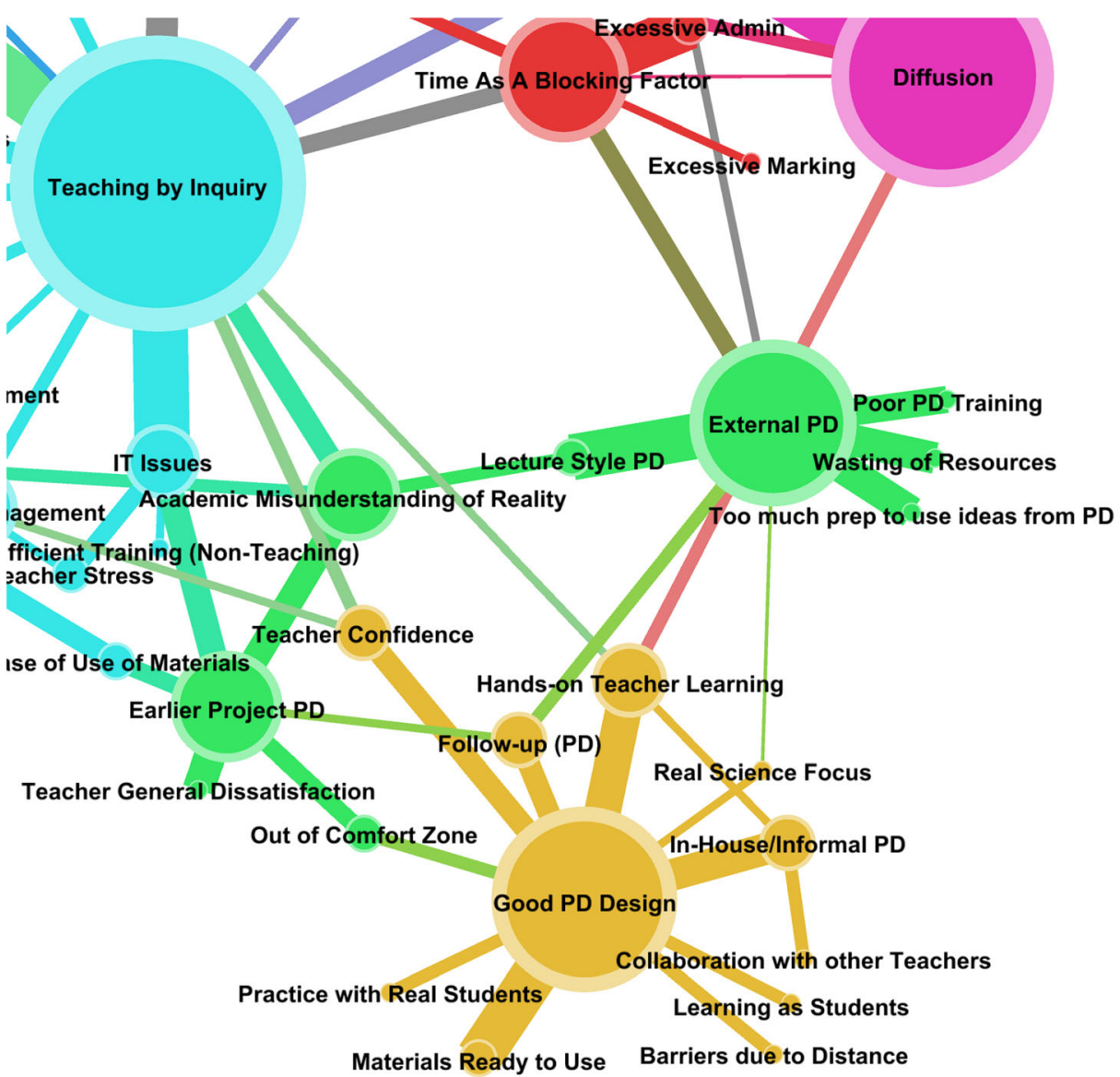

Fig. 4 "Actual" and "ideal" professional development themes and connected concepts

momentum, but once they return to the reality of the school, there is little chance to incorporate any of the ideas garnered from the day. This is largely because these sessions commonly do not give teachers something concrete that they can take directly back to their classrooms. Rather, any content or materials to be implemented require significant preparation involving both time and resources. There also seems to be little science-focused PD for teachers in comparison to more generalised pedagogical, legal, or administrative professional development.

Professional development, what I'm finding with people is that they've reached saturation point...the first day back next term, we've got to do professional development. We've got to do three sessions. And the choices, like a lot of them, are basic computing skills. Sorry, I don't want to spend an hour learning something that I'm not going to use straight away because I can work things out for myself anyway and to waste an hour of my time when I'm not going to be using it straight away, when I will forget, to me, is a waste of my time. $\left(\mathrm{T}_{3}\right)$

and

I hate going on PD days. I hate them, because they're usually educational based. I like going to PD days where you learn some science, and then you learn how to fit the 
science into education, rather than "this is how you teach" and then you've got to try and fit your science into the teaching method, and it's usually a day that you sit there and think you could have done a lot more with it. $\left(\mathrm{T}_{6}\right)$

In general, the PD provided in the earlier project period (pre-August 2010) suffered from the same problems illustrated above. There was widespread teacher dissatisfaction with the PD and with the project as a whole. However, there was one specific and important area that emerged from this theme. This was that the concept of academics' misunderstanding of reality. In this earlier phase of the project, the misunderstanding appears to have been particularly pronounced. Some teachers commented that the project expected from both them and their students was "light years away" from what would actually be achievable in their classrooms.

A significant proportion of this tension was due to the teachers being asked to go far beyond their comfort zone and without sufficient scaffolding or support being provided. The teachers felt that they, and their students, were being asked to "actually be astronomers". Neither they, who at best had a broad generalist science expertise, nor their students, who typically did not even know what a galaxy was, could undertake a real piece of scientific research in the very limited class time available to astronomy. While some (very few) teachers thrived on this expectation, the vast majority thought it was an implausible and unachievable approach.

Initially it [the PD] assumed too much knowledge for the teachers. They do know stuff, but they don't know all the stuff that the astronomy department of M- University knows as part of their cultural knowledge and, you know, I think it was too high. The expectation was that you astronomers are there (points slightly high) the kids are there (points to the middle), you think we are there (in between the astronomers and students) and you want us to go there (where the astronomers are) but we are really there (points very low) and the kids are really there (even lower), so the gap was a lot higher than what you thought. $\left(\mathrm{T}_{7}\right)$

Teachers also see quite distinct contrasts between what they were taught during their teacher education degrees (e.g. constructivism, inquiry-based methods) and the reality (e.g. transmission, tick the box teaching methods) when they were thrust into in their mainstream teaching careers. They also see this distinction between what they can achieve in their classrooms and what gets presented to them by academics.

.... you know our feeling, probably amongst teachers, is that academics couldn't teach if their life depended on it. That's our feeling as teachers and she [reference made to an academic] did everything in her power to confirm that. We still talk about it because it was meant to be about quality teaching and we all went to the hall and sat there and listened while she stood at her lectern and lectured us for six hours. Half the teachers didn't even turn up after lunch. You know, that's pretty poor isn't it? $\left(\mathrm{T}_{7}\right)$

My first couple of years [of teaching], it was like...this is not what I've been learning at university in some ways, the new way of facilitating learning and all of that. So I've been six years down the track. I feel like I'm now a teacher in one of those schools. To be honest, I think I've lost touch with what I have learnt, a bit, at university in the whole constructivist type approach to learning. And now I follow a program and tick the outcomes off and that's kind of my focus, it seems. $\left(\mathrm{T}_{8}\right)$ 


\section{Good PD Design}

In contrast to the actual theme of $\mathrm{PD}$, the ideal theme in orange provides us with a set of connected concepts (Fig. 5). It reinforces what has been called for within the science education reform literature over a number of decades but which is not commonly enacted within the classroom (Goodrum et al. 2001, Danaia et al. 2013). That is to say, teachers should actively learn in similar ways to their students in the context of the relevant content focus and in collaboration with other teachers in ways that boost the teacher's confidence. In-school or informal PD is seen as more beneficial than external days which are hampered by barriers due to distance. At the end of any PD day, teachers should expect to go home with something they could take into the class "tomorrow" with systematic evaluation in the weeks following to reconnect and make their implementation and learning concrete.

Apart from a very small number of trailblazers, most teachers lacked the confidence to undertake the project in its previous form. However, the teachers were uniformly very positive about the reformed version of the project (post-August 2010) provided to them and the confidence they now felt. The teachers still commented about being "out of their comfort zone" but noted it as a positive feeling rather than a negative one.
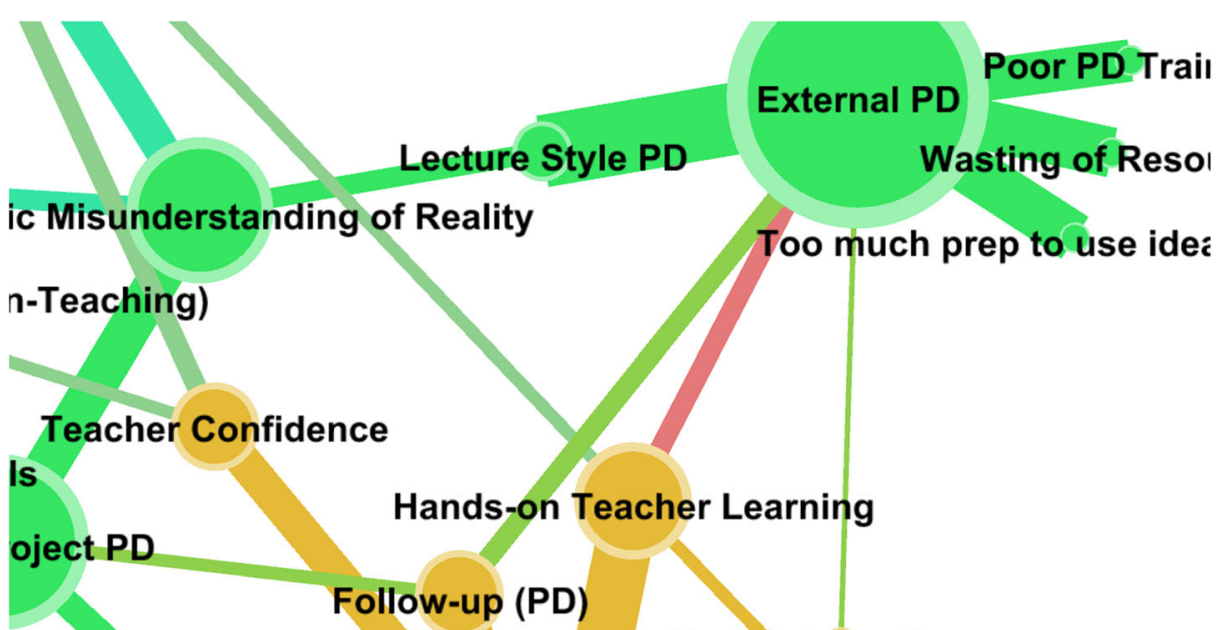

ssatisfaction

Real Science Focus

Out of Comfort Zone

In-House/Informal PD

Good PD Design

Collaboration with other Teachers

Practice with Real Students

\section{Materials Ready to Use Barriers due to Distance}

Fig. 5 "Ideal" professional development theme and connected concepts 
I found them [the PD days] extremely useful and I got more and more confident. As you know, I was the one who was like, "I can't get this" and it sort of made me learn too... and then I learnt a lot from my mistakes. So when a student actually did make a mistake in class, I remembered doing it during the professional development and I knew how to resolve it. $\left(T_{9}\right)$

The later professional development design was much slower paced than the typical PD sessions teachers had experienced and on which they had commented negatively. The PD sessions focused heavily on getting the teachers to undertake the same processes, using the same materials, as their students would be required to do. There was also a heavy science content focus as well. The majority of the session times were spent with the teachers actively using the materials as learners with periods of time for reflection about how they would undertake this" in their class. During these periods, various pedagogical approaches such as guided inquiry and jigsaw methods were discussed in light of their very recent experience of doing it. A further benefit of the newer design was that it involved multiple face-to-face sessions with collaborative homework undertaken in an asynchronous online fashion. This allowed for the teachers' feedback to be incorporated into the subsequent session. The sequence of PD sessions allowed the teacher to return to the material multiple times with the benefit of increased experience and some reflection derived from their previous sessions.

Because I could see I could use it, and that's what matters in teaching because in teaching the worst thing... people give you all these great ideas and then it just...nothing ever happens with it. Whereas with this, I could implement this tomorrow, I've got the material... and I've done it all myself too. It's not like I'm coming from a theoretical point of view. I can do this, I've done it in class, I was the naughty boy at the back [during the PD], so that's cool. I can do it. $\left(\mathrm{T}_{10}\right)$

I just think unless there's follow-up, then you tend to, well I tend to go... Okay that's nice... and then it gets put to one side. There's no change in [my] behaviour. You might think it's all well and good, but then it all gets put aside because you've got these commitments to get work done to a timeframe and it just gets put aside, even though what you've done might be relevant, might be great. Unless you've spent the time to actually adapt it, you're not going to do it. But for me, if there's follow up, you're going to make some effort to adapt. $\left(\mathrm{T}_{3}\right)$

Of particular note was the fact that the materials were ready to use in the classroom. After each training day, the teacher was capable of taking the material directly into their classroom, and some of them had, to use with their students. These materials required only minor modification for a particular context/classroom. This was an important issue on which teachers commented frequently and positively. They contrasted this approach with their previous PD experiences where "adequate" resources or pedagogical approaches ready for classroom use were not provided.

... and particularly things with resources and new sort of ideas. They give you the resource but no real...they don't tell you anything about how to implement it or how to use it. So generally, they just give you a resource and then you go away and work out how you're going to structure [it] into lessons what the kids [are to] do and what you'll need to do, etcetera. Whereas [with] this package, it's already designed and set up for us to implement. $\left(T_{11}\right)$

In general and in contrast to their earlier traditional external experiences, teachers seem very positive about in-house and informal PD and its increased benefits. As one teacher said, 
"Sometimes a five-minute chat over the coffee table can improve your teaching much better than an entire PD day". One teacher involved in the project has constructed his own PD website to provide a forum for teachers to share their ideas and to collaborate with other teachers over the implementation of the project materials. In one sense, this is almost like having that 5-min chat over morning coffee.

...here in the past our teachers have delivered [In-house PD sessions] them, especially on different educational projects that they've delivered and that's been good. Everyone's engaged because they're your colleagues and it's what's working in their classroom so you're interested in it. They've done it with our kids, the same sort of kids that we would have in our room, and it's worked, and they've got measurable improvements that are actually real to us, and I'm sure the other ones are real as well but when we know the kid and they can say, "Look, he's gone from here to here by doing a few of these tasks," well then it's real, and so everyone's engaged. $\left(\mathrm{T}_{12}\right)$

\section{Curriculum-Related Barriers}

When the conversation turns to taking the new inquiry-based learning into their actual classroom, a broad theme (red) describes a cluster of factors preventing the spread or diffusion (purple) through the general teacher population. Dealing with the specific barriers first, we see that the three major concepts that emerge are the form of the "curriculum or syllabus", "time", and its very heavy linking with "excessive admin" (Fig. 6).

"Time" is the most commonly stated single factor preventing project implementation. A large amount of time is actually spent teaching the students (five out of every six periods). This leaves one period for preparation per day in the typical school. This single period is usually

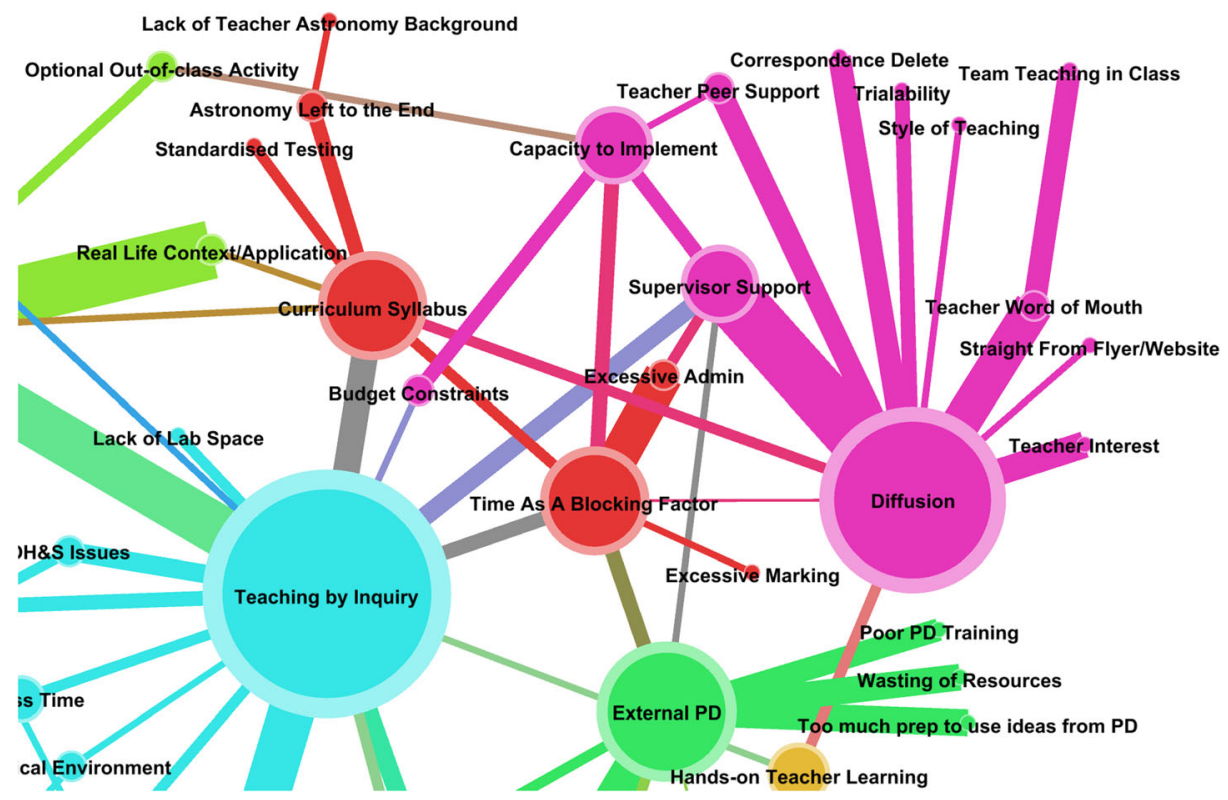

Fig. 6 "Curriculum-related factors" and "diffusion" themes and connected concepts 
spent catching up on administrative tasks while the class preparation work is generally left until the teacher returns home in the evening or conducts it at the weekend.

[Time as an issue]...look it is, but it's not enough to say that time is an issue because it's becoming a more significant issue and the way schools are going at the moment with the expectations from the Department [of Education], teachers are going to have less and less available time. They are chasing their tails on often pointless administrative bloody crap, you know, and they are using their energy arguing with resistant dysfunctional kids. And that's not a good environment to be trying to generate a sense of inquiry or wanting to get out there and learn more, or improve your teaching. People pull back when those sorts of pressures start to mount and they are mounting significantly. $\left(T_{13}\right)$

It [time] is a big issue and the workload is actually the thing that people complain about. It's not necessarily doing something new, it's how much work is involved. Well I was just saying the other day, like I get in here about quarter past seven and I'm often here till after five and then I go home and do a couple of hours work. So I guess a 12-hour day and the weekends, it's a big ask...it's, yeah, not getting any easier. So yeah, it's very time consuming and yeah that's why I didn't really want to take on something new [the project] that would take up even more of my time. $\left(\mathrm{T}_{14}\right)$

While teachers do not so much mind the out-of-hours preparatory work, they have found that the amount of administration and paperwork to be completed has been steadily increasing as outside agencies want them to become more accountable. However, some teachers pointed out that this additional "administrivia" either generates an elaborate system of lying or simply taxes a teacher's time and intellectual resources with no actual benefit either to the teacher or to the student. Even the mandatory content of the curriculum is sometimes not being undertaken as a coping strategy for teachers. Marking and the provision of feedback are seen as major time sinks but the lesser of the two evils. Some teachers commented that it would help a great deal to have someone actually do some of the more mundane tasks such as enter the assessment marks into the computer for them.

The thing I just don't like about teaching is the administration part of teaching. We are getting really bogged down with that these days. So, at the moment, many teachers are spending a lot of hours doing work to be compliant for an audit. So taking work samples from students' work, a lot of fiddling around with [the science] programs and a lot of the stuff is bureaucratic stuff. I don't mind doing stuff if I see a positive for it, like if, for example, if you are doing all this stuff for the audit and someone comes back and says I don't agree with these activities you are doing, or the way you are teaching this, here are some other strategies, then that's fine. But if you just do all this work and there is no response, you think, what's the point? $\left(T_{9}\right)$

Well it's impossible. It's impossible to do everything that's asked of you. I've never been able to do the job, but I'm relaxed about that because I know there are things I'm not doing, as long as somebody else doesn't know I'm not doing it. Well, everybody is doing it. The only difference is generally that I'm being honest about it and say I'm not doing it all. But, there are plenty of teachers that like to give you the impression that they're on top of it. So we are creating an environment where you can't do it, but you can only be rewarded if you make it look like you are doing it all. It's another stress isn't it. It's very poor management that one! $\left(\mathrm{T}_{3}\right)$

The administration and preparation pressures are intertwined with the overcrowded nature of the curriculum and the national testing regime that structures the school program and which dictates the nature of the use of scheduled class time. In terms of astronomy, the topic is 
generally left until the end of the year in their science program. As some teachers claimed, this means that it is just not done. In general though, if the project cannot be adequately and easily fitted into the school's program, which is usually very tight, it is unlikely to be taken up.

First of all is the nature of the science syllabus. It's huge and there's like heaps and heaps of stuff in there. And although the science syllabus is described that you would spend 50 per cent of your time on pure skills and only really 25 per cent of your time on just straight-up knowledge content, in reality there's so much content to get through that it's very easy sometimes to spend all your time on content. So, the first thing is of course there's so much to get through that we don't get the time to actually do proper experiments, and we don't get the time to do more interesting and fun things. We really don't...like I haven't been on an excursion for science in my teaching career. I haven't been on one because there's no time. The schools just don't have the time to put aside a day for science. And that's significant. $\left(\mathrm{T}_{8}\right)$

\section{Diffusion}

Parts of the discussions revolved around what had aided or hindered other teachers, and themselves, from implementing the project. The "purple" theme focussed on "diffusion" generally outlines how teachers perceived inquiry-based teaching as successfully spreading through the population (Fig. 7). By far, the strongest element was having support from a

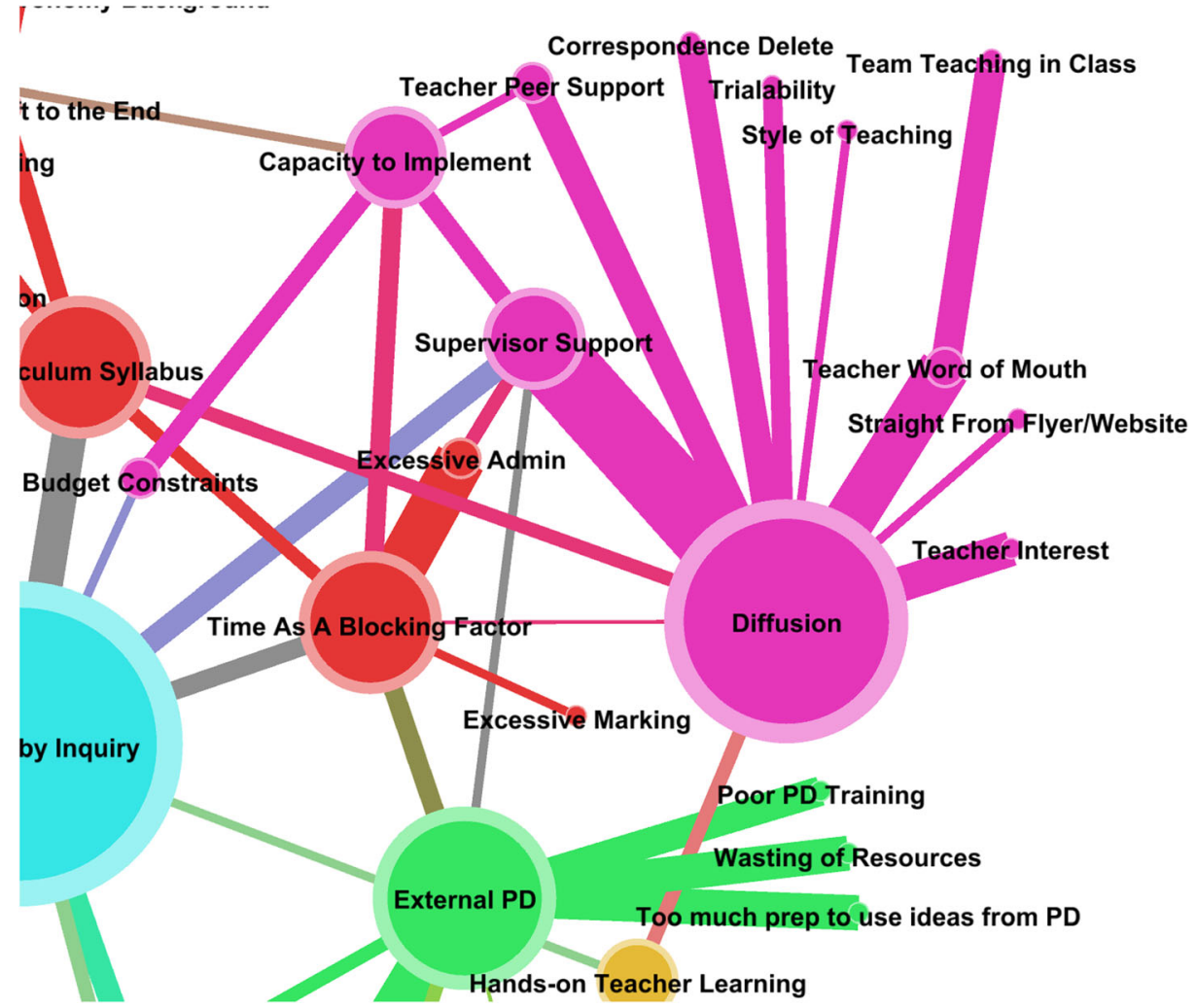

Fig. 7 "Diffusion" theme and connected concepts 
relevant higher authority, whether in the school or the jurisdiction and with strong support from other teachers. Teachers tended to be more comfortable with getting involved if they were recommended to do so by another teacher and found that being invited to visit and observe another teachers' classroom as quite motivating.

While fellow teachers can form a strong supportive social group as well as being a source of information through personal conversations, it is generally a person in a supervisory position who is a key facilitator for that teacher to participate in the project. In contrast, there were teachers who said they specifically asked for certain allocations or classes in order to be able to incorporate the project but were denied their requests.

Yes, and a few administrative issues, like I had specifically requested to be on [particular classes] this year. I also specifically requested to teach Year 10 this year to really get it embedded. But that didn't happen...neither of those requests. So it will be a challenge to take it beyond where we were last year. $\left(\mathrm{T}_{15}\right)$

Being the only person interested in the project at a school has also been perceived as a negative factor. Having another teacher at the same school to share resources, to have conversations with, and to show support makes implementation much easier. Some teachers who have had previous positive experiences with the project have invited other teachers into their class or have gone into other teachers' classes to show them how the project works in reality. This provides the new teacher with some experience of what is required and an ability to undertake a particular project as an exploratory trial.

I would've been happy to go with it if someone else on my staff had been interested, and no one was. I just felt like "it's just another thing I've got to do" and I was already drowning and having trouble keeping my head above water. So that's the reason, it's not a very exciting reason and each time something's come up but no one wants to be involved. $\left(\mathrm{T}_{15}\right)$

Only very occasionally did a teacher become involved from encountering information in the form of a flyer or the project website. Generally, it was more likely for a teacher to become involved through the recommendation of a trusted peer or supervisor. Typically, teachers are swamped with correspondence aimed at getting them to be involved in all manner of projects or for enticing them to make any number of purchases. Usually, this correspondence is ignored or discarded due to the time constraints alluded to earlier.

Well yeah, look, that's...I undoubtedly delete some stuff that I might vaguely be interested in, just because of the sheer quantity. It's personal recommendation; it's like anything, isn't it? If you want to go and buy a phone it's nice to be able to see someone who's had it and, yeah, and knows all the ins and outs about it. So a personal recommendation is much more useful. So, I think it's that personal side. We often listen to each other more than we read every email that comes across our desk. $\left(\mathrm{T}_{16}\right)$

A teacher's intrinsic interest is not enough by itself to provide the motivation to implement. With the earlier materials (pre-2010), some teachers who were particularly interested in astronomy were put off from undertaking the project and sometimes by the lack of supervisor or peer support. While these lie in the personal domain, the intrinsic domain is never absent. Science departments are frequently starved of adequate funds to undertake initiatives that may lead to higher levels of engagement not only of their students but also of themselves. The final 
quotation starkly underscores the lack of investment in science education. Budgets of this magnitude are common and an indictment of the system.

That doesn't mean we don't want to teach [that] boring science. We'd like to, my budget to run the science faculty is $\$ 9000$ a year. You go back to your astronomy department and ask them how much they've got to run their department...\$9000 a year...that's for all the textbooks, all the equipment, all the stationery for 400 kids. That's not much money. $\left(\mathrm{T}_{17}\right)$

\section{Summary and Discussion}

This research has drawn on teachers' perspectives to identify factors that they perceive prevent them from implementing inquiry-based learning and teaching approaches in secondary school science classes. Analysis of the 34 teacher interviews revealed that while many were familiar with the term inquiry-based learning, some were not sure about what it would involve in the reality of their own classrooms. Consistent with other research (Garet et al. 2001), many lacked the confidence and competence to implement inquiry approaches within their science classes. Teachers also indicated that they have little time to implement inquiry-based, investigative approaches given the breadth of the curriculum that had to be covered.

One of the most basic concerns identified in this research was that teachers were not even quite sure what inquiry-based learning actually meant. As found in other studies, just noting that inquiry must be undertaken in the curriculum documentation certainly does not lead to inquiry implementation in the classroom (Abd-El-Khalick et al. 2004).

All of the factors identified have implications for both pre-service teacher training and inservice teacher professional development. It would seem that teachers not only need extensive support and guidance on how they could implement inquiry-based instructional approaches within their classrooms, they also need examples, models, and actual experience in implementing them before attempting to do so within their own science classes. In this project, all of the teachers who experienced implementing such approaches during the professional development sessions later implemented these inquiry-based investigative approaches in their classroom and continue to do so (Fitzgerald et al. 2016). It is also worth noting that some are applying inquiry-based approaches to other science content to be covered and not just to the astronomy content of the project.

Curriculum developers and policy advisors may conclude from these findings that if inquiry-based approaches are to be implemented successfully in the delivery of secondary school science, the breadth of the curriculum needs to be reduced to allow teachers time to cover the content at depth and to focus on implementing it using inquiry-based approaches. More importantly, and perhaps centrally, teachers need to be engaged in professional development that both models and involves them in investigative, inquiry-based approaches.

Similar to other Western countries, Australia now has a set of National Professional Standards for Teachers. One of these standards requires teachers to engage in continuedprofessional development. Within Australia, state- and territory-based educational bodies exist that require teachers to be accredited. To be accredited and to maintain accreditation with the regulating body, teachers must undertake a specified number of hours of professional development within a particular time frame. This is happening at a time where Australian teachers are also confronted with the roll out of a national curriculum. The new Australian science 
curriculum, which is now mandatory, calls for investigative science and inquiry-based learning approaches to be adopted.

Given these circumstances, it is now opportune to examine current models of scienceteacher professional development in light of the factors identified above. Moreover, it is also time to transform the more traditional, transmissive instructional approaches commonly employed in secondary school science classes to ones that involve students and their teachers investigating and engaging in inquiry-based learning. This is a major issue for such approaches where teachers who do adopt and implement them are those who are willing to take risks and self-organise within schools where such activities are actively supported by their administration (Songer et al. 2001). Even so, for these teachers, their opinions of what PD facilitators ask them to do are negative with many of the demands placed on them being regarded as completely unrealistic.

Even when the claims and rhetoric of those who deliver the PD are potentially realistic, the quality, and nature, of the training provided is often problematic, lacking in the five key broad characteristics of effective PD identified by Ingvarson et al. (2005): be content focused, involve active learning, provide feedback, involve collaborative examination of student work, and have long-term follow-up. The teachers interviewed in this study had counted themselves lucky to have experienced even one of these in their previous PD sessions. Similar lists of quality characteristics by other authors, such as Supovitz and Turner (2000), Banilower et al. (2007), Loucks-Horsley et al. (2003), Garet et al. (2001), and Meiers and Ingvarson (2003), differ little in their substance as to what constitutes "good" PD and in their claims about their lack of presence within the typical teacher PD experience in this study.

Professional development, however, does not exist in a vacuum. As also found by Johnson (2006), even when a high-quality professional learning experience is provided, there are still a large number of technical, political, and cultural barriers to implementation. It should be noted that the teachers within this study did not express any scepticism of inquiry-based learning as an approach in itself (leaving aside the problems with its definition), but concerns were largely focussed around their capacity to implement it in the real school classroom with these barriers surrounding it. As these teachers were early adopters in an implementation, it is very likely that they were also positively disposed to the intended path of the project already and had bought in. In a sense, then, the barriers identified in this study represent a minimum of the concerns that should be addressed in attempting a large-scale inquiry-based project.

The interviews also revealed that typical professional development experiences fail to model the behaviours at which they are directed such as inquiry-based learning or constructivist pedagogies. Rather, they are transmissive in nature and appear to have little, if any, impact on teachers' classroom practices. Many of these concerns have been consistently reported in the literature together with numerous calls for change to the way in which secondary school science is delivered (e.g. Goodrum et al. 2001; Goodrum \& Rennie 2007; Marshall et al. 2016; Tytler 2007).

Some of these technical, political, and cultural barriers include large class sizes, limited resources, and space, ever tighter occupational health and safety regulations, and excessive administrative loads within the school context that prevented teachers from employing inquirybased instruction. These are not uncommon barriers to be identified in such studies (e.g. Songer et al. 2002). The actual mechanics of classroom management also represent a significant shift from traditional classroom activity (Harris \& Rooks, 2010).

Some of the issues that did not arise in this study were the influence of parents on implementation (Anderson \& Helms 2001). Parents were discussed in these interviews in the 
context of the students, their subject choice, and their decline in interest, but there were no links made between this and their capacity to implement inquiry-based learning in class. In fact, there was little linking made, as can be seen in Fig. 1, between issues surrounding these student-related concepts and the largely school, teacher, and classroom considerations. The most significant links between the two sets of concepts were between inquiry, student motivation, and curriculum issues and the different achievement levels of students. This likely indicates that these teachers were so far still largely concerned with the more fundamental question of "how will this work in the classroom?" rather than more sophisticated questions about the resulting impact on students.

Once a sufficient level of professional development has been achieved, even more attention needs to be paid to contextual factors such as the primacy of teachers' time and its relation to the stress levels reported by science teachers and the quality of work they produce. Inquirybased learning, by definition, takes more time, preparation, and expertise by the teacher, than traditional transmissive teaching. The current, seemingly common, culture of science teachers where there is insufficient time to implement approaches that are absolutely required by the curriculum is not an environment conducive to implementing sophisticated inquiry-based projects in class. Regardless of the nature of the PD, if the teacher exists within a context that prevents adequate translation of what was learnt in the professional development session into the classroom, then it and all of the associated expense were all for naught.

Acknowledgements We acknowledge the project from which the teacher data are drawn: Space to Grow Australian Research Council Linkage Grant (grant number: LP0989264). MF acknowledges receipt of MQRES $\mathrm{PhD}$ scholarship from Macquarie University.

Open Access This article is distributed under the terms of the Creative Commons Attribution 4.0 International License (http://creativecommons.org/licenses/by/4.0/), which permits use, duplication, adaptation, distribution and reproduction in any medium or format, as long as you give appropriate credit to the original author(s) and the source, provide a link to the Creative Commons license, and indicate if changes were made.

\section{References}

Abd-El-Khalick, F., Boujaoude, S., Duschl, R., et al. (2004). Inquiry in science education: international perspectives. Science Education, 88, 397-419.

American Association for the Advancement of Science (AAAS), (1990). Science for all Americans: project 2061. New York: Oxford University Press.

Anderson, R. D., \& Helms, J. V. (2001). The ideal of standards and the reality of schools: needed research. Journal of Research in Science Teaching, 38(1), 3-16.

Australian Curriculum and Assessment Reporting Authority (ACARA), (2014). Foundation to year 10 curriculum. Retrieved from http://www.australiancurriculum.edu.au/

Australian Government: Department of Education and Training. (2014). Review of the Australian curriculum final report. Canberra: Australian Government.

Townsend, A., McKinnon, D., Fitzgerald, M., Morris, J., \& Lummis, G. (2017). Educative curricula and PCK development driven by STEM professional learning in rural and remote schools: a longitudinal Type IV Case Study. International Journal of Innovation in Science and Mathematics Education, 24(4), 1-17.

Danaia, L., McKinnon, D., Parker, Q., Fitzgerald, M., \& Stenning, P. (2012). Space to grow: LCOGT.net and improving science engagement in schools. Astronomy Education Review, 11(1), 010106.

Danaia, L., Fitzgerald, M., \& McKinnon, D. (2013). Student perceptions of high school science: what has changed over the last decade. Research in Science Education, 43(4), 1501-1515.

Fitzgerald, M., Hollow, R., Rebull, L., Danaia, L., \& McKinnon, D. (2014). A review of high school level astronomy student research projects over the last two decades. Publications of the Astronomical Society of Australia 31, e037. https://doi.org/10.1017/pasa.2014.30. 
Fitzgerald, M., McKinnon, D., \& Danaia, L. (2015). Inquiry-based educational design for large-scale high school astronomy projects using real telescopes. Journal of Science Education and Technology, 24(6), $747-760$.

Fitzgerald, M., McKinnon, D., Danaia, L., \& Deehan, J. (2016). A large-scale inquiry-based astronomy intervention project: impact on students' content knowledge performance and views of their high school science classroom. Research in Science Education, 46(6), 901-916.

Banilower, E., Heck, D., \& Weiss, I. (2007). Can professional development make the vision of the standards a reality? The impact of the National Science Foundations's local systemic change through teacher enhancement initiative. Journal of Research in Science Teaching, 44(3), 375-395.

Blank, R. K., de las Alas, N., \& Smith, C. (2008). Does teacher professional development have effects on teaching and learning? Evaluation findings from programs in 14 states. Washington, D.C.: Council of Chief State School Officers.

Blondel, V.D., Guillaume, J-L, Lambiotte, E., Lefebvre, E. (2008), Fast unfolding of communities in large networks, Journal of Statistical Mechanics, P10008

Bonwell, C.C., Eison, J.A., (1991), Active learning: creating excitement in the classroom. 1991 ASHRE-ERIC Higher Education Report No. 1. Washington D.C.: The George Washington University, School of Education and Human Development.

Brown, T. M., Baliber, N., Bianco, F. B., et al. (2013). Las Cumbres Observatory Global Telescope Network. Publications of the Astronomical Society of the Pacific, 125, 1031.

Bybee, R. W. (1997). Achieving scientific literacy: from purposes to practical action. Portsmouth, NH: Heinemann.

Bybee, R. W., Taylor, J. A., Gardner, A., Scotter, P. V., Powell, J. C., Westbrook, A., \& Landes, N. (2006). The BSCS 5E instructional model: origins and effectiveness. Colorado Springs, CO: BSCS.

Capps, D. K., \& Crawford, B. A. (2013). Inquiry-based instruction and teaching about nature of science: are they happening? Journal of Science Teacher Education, 24, 497-526.

Capps, D. K., Crawford, B. A., \& Constas, M. A. (2012). A review of empirical literature on inquiry professional development: alignment with best practices and a critique of the findings. Journal of Science Teacher Education, 23(3), 212.

Committee for the Review of Teaching and Teacher Education (CRTTE), (2003). Australia's teachers: Australia's future advancing innovation, science, technology and mathematics agenda for action. Canberra: Department of Education, Science and Training.

Commonwealth Government (2007), Top of the class: report on the inquiry into teacher education. Canberra.

Darling-Hammond, L., Chung-Wei, R., Andree, A., \& Richardson, N. (2009). Professional learning in the learning professions: a status report on teacher development in the United States and abroad. Oxford, OS: National Staff Development Council.

Department of Education, Science and Training (DEST) (2006) Summary report of the science, engineering \& technology skills audit. Canberra: Commonwealth of Australia

Dillon, J., Osborne, J., Fairbrother, R., Kurina, L., (2000), A study into the professional views and needs of science teachers in primary and secondary schools in England. Kings College London

Drury, C., \& Allen, A. (2002). Task force on the physical sciences: report and recommendations. Ireland: Department of Education and Science.

European Commission. (2007). Science education now: a renewed pedagogy for the future of Europe. Brussels, Belgium: European Commission, Directorate General for Research.

Furtak, E. M., Seidel, T., Iverson, H., \& Briggs, D. C. (2012b). Experimental and quasi-experimental studies of inquiry-based science teaching: a meta analysis. Review of Educational Research, 82(3), 300-329.

Furtak, E. M., Shavelson, R. J., Shemwell, J. T., \& Figueroa, M. (2012a). To teach or not to teach through inquiry: is that the question? In S. M. Carver \& J. Shrager (Eds.), The journey from child to scientist: integrating cognitive development and the education sciences (pp. 227-244). Washington, DC: American Psychological Association.

Garet, M., Porter, A., Desimone, L., Birman, B., \& Yoon, K. (2001). What makes professional development effective? Results from a national sample of teachers. American Educational Research Journal, 38(4), $915-945$.

Goodrum, D., \& Rennie, L. (2007). Australian school science education national action plan $2008-2012$. Canberra: Department of Education Science and Training.

Goodrum, D., Hackling, M., \& Rennie, L. (2001). The status and quality of teaching and learning of science in Australian schools: a research report. Canberra: Department of Education, Training and Youth affairs.

Hall, G., \& Hord, S. (2001). Implementing change: patterns, principles, and potholes. Needham Heights: Allyn and Bacon.

Harris, C. J., \& Rooks, D. L. (2010). Managing inquiry-based science: challenges in enacting complex science instruction in elementary and middle school classrooms. Journal of Science Teacher Education, 21, 227-240.

Herron, M. D. (1971). The nature of scientific inquiry. School Review, 79(2), 171. 
Ingvarson, L., Meiers, M., \& Beavis, A. (2005). Factors affecting the impact of professional development programs on teachers' knowledge, practice, student outcomes \& efficacy. Educational Policy Analysis Archives, 13, 10.

International Bureau for Education. (2001). Science education for contemporary society: problems, issues and dilemmas. Geneva: International Bureau for Education, UNESCO.

Jacomy, M., Heymann, S., Venturini, T., Bastian, M., (2011 DRAFT), ForceAtlas2, a graph layout algorithm for handy network visualization, DRAFT ONLINE :http://www.medialab.sciences-po.fr/publications/Jacomy_ Heymann_Venturini-Force_Atlas2.pdfpdf

Johnson, C. C. (2006). Effective professional development and change in practice: barriers science teachers encounter and implications for reform. School Science and Mathematics, 106(3), 150-161.

Kirschner, P. A., Sweller, J., \& Clark, R. E. (2006). Why minimal guidance during instruction does not work: an analysis of the failure of constructivist, discovery, problem-based, experiential, and inquiry-based teaching. Educational Psychologist, 41, 75-86. https://doi.org/10.1207/s15326985ep4102_1.

Krajcik, J., Blumenfeld, P., Marx, R., \& Soloway, E. (2000). Instructional, curricular, and technological supports for inquiry in science classrooms. In J. Minstrell \& E. H. van Zee (Eds.), Inquiry into inquiry learning and teaching in science (pp. 283-315). Washington, DC: American Association for the Advancement of Science.

Loucks-Horsley, S., Love, N., Stiles, K., Mundry, S., \& Hewson, P. (2003). Designing professional development for teachers of science and mathematics. London: Sage Publications.

Lumpe, A., Haney, J., \& Czerniak, C. (2000). Assessing teachers' beliefs about their science teaching context. Journal of Research in Science Teaching, 37(2), 275.

Lupton, M. (2014). Inquiry skills in the Australian curriculum v6: a birds-eye view. Access, 28, 8-29.

Marshall, J. C., Smart, J. B., \& Alston, D. M. (2016). Inquiry-based instruction: a possible solution to improving student learning of both science concepts and scientific practices. International journal of science and mathematics education. https://doi.org/10.1007/s10763-016-9718-x.

Mayer, R. E. (2004). Should there be a three-strikes rule against pure discovery learning? The case for guided methods of instruction. American Psychologist, 59, 14-19. https://doi.org/10.1037/0003-066X.59.1.14.

Meiers, M., Ingvarson, L., (2003), Investigating the links between teacher professional development and student learning outcomes,

Millar, R., \& Osborne, J. (1998). Beyond 2000: science education for the future (the report of a seminar series funded by the Nuffield Foundation). London: King's College London, School of Education.

National Research Council. (2000). Inquiry and the national science education standards. Washington, DC: National Academy Press.

NGSS Lead States. (2013). Next generation science standards: for states, by states. Washington, DC: The National Academies Press.

Osborne, J. (2006). Message from the President E-NARST News, 49, 1-2.

Penuel, W., Fishman, B., Yamaguchi, R., \& Gallagher, L. (2007). What makes professional development effective? Strategies that foster curriculum implementation. American Educational Research Journal, 44, 921.

Schwab, J. J. (1962). The teaching of science as inquiry. In J. J. Schwab \& P. F. Brandwein (Eds.), The teaching of science. Cambridge, MA: Harvard University Press.

Select Committee on Science and Technology (2002). Science Education from 14 to 19, House of Commons: UK Parliament.

Settlage, J. (2007). Demythologizing science teacher education: conquering the false ideal of open inquiry. Journal of Science Teacher Education, 18, 461.

Songer, N., Lee, H., \& McDonald, S. (2001). Research towards an expanded understanding of inquiry science beyond one idealized standard. Science Education, 87(4), 490.

Songer, N. B., Lee, H., \& Kam, R. (2002). Technology-rich inquiry science in urban classrooms: what are the barriers to inquiry pedagogy? Journal of Research in Science Teaching, 39(2), 128-150.

Supovitz, J., \& Turner, H. (2000). The effects of professional development on science teaching practices and classroom culture. Journal of Research in Science Teaching, 37(9), 963-980.

Tytler, R. (2007). Re-imagining science education: engaging students in science for Australia's future. Camberwell: Australian Council for Education Research.

Yoon, K.S., Duncan, T., Lee, S.W.Y., Scarloss, B., Shapley, K. (2007). Reviewing the evidence on how teacher professional development affects student achievement (Issues and Answers Report, REL 2007 No. 033). Washington D.C.: U.S. Department of Education, Regional Educational Leaboratory Southwest. 